\title{
Referenciamento territorial de políticas sociais e reconfiguração do sistema educativo no Brasil
}

Territorial referencing of social policies and reconfiguration of the education system in Brazil

Referenciamento territorial de políticas sociales y reconfiguración del sistema educativo en Brasil

Territorialisation des politiques sociales et réconfiguration du système scolaire au Brésil

\section{Eveline Algebaile, Gustavo Leite de Araújo da Silva e Tacílio Fagundes}

\section{OpenEdition}

Journals

Edição electrónica

URL: http://journals.openedition.org/espacoeconomia/1257

DOI: $10.4000 /$ espacoeconomia. 1257

ISSN: 2317-7837

Editora

Núcleo de Pesquisa Espaço \& Economia

Refêrencia eletrónica

Eveline Algebaile, Gustavo Leite de Araújo da Silva e Tacílio Fagundes, «Referenciamento territorial de políticas sociais e reconfiguração do sistema educativo no Brasil », Espaço e Economia [Online], 5 | 2014, posto online no dia 26 dezembro 2014, consultado o 10 junho 2020. URL : http:// journals.openedition.org/espacoeconomia/1257 ; DOI : https://doi.org/10.4000/espacoeconomia. 1257

Este documento foi criado de forma automática no dia 10 junho 2020. 


\title{
Referenciamento territorial de políticas sociais e reconfiguração do sistema educativo no Brasil
}

\author{
Territorial referencing of social policies and reconfiguration of the education \\ system in Brazil \\ Referenciamento territorial de políticas sociales y reconfiguración del sistema \\ educativo en Brasil \\ Territorialisation des politiques sociales et réconfiguration du système scolaire \\ au Brésil
}

Eveline Algebaile, Gustavo Leite de Araújo da Silva e Tacílio Fagundes

\section{Introdução}

1 As alterações na organização da ação estatal ocorridas com a reestruturação do capitalismo, a partir dos anos 1970, mostram-se visíveis, entre outros aspectos, nas formas de definir a cobertura populacional e o "referenciamento territorial" ${ }^{\text {das }}$ políticas sociais, aqui entendido como o conjunto de referências territoriais que balizam a organização de serviços, equipamentos e ações públicas constitutivos dessas políticas.

2 Ainda que as políticas sociais estruturadas no contexto anterior, marcado pela referência ao Estado de Bem Estar Social, mantenham orientações de alcance populacional e territorial típicas da perspectiva universalista (orientada para o acesso de todos os cidadãos), observa-se, no interior dessas políticas e nas chamadas "políticas de nova geração", a emergência de formas de referenciamento territorial regidas por propósitos de focalização (ou seja, de cobertura seletiva de segmentos sociais ou territoriais) que podem implicar efetiva diminuição da presença do Estado no campo social. Apesar das evidências dessa redução, parte das discussões sobre o tema vem 
enfatizando os aspectos considerados positivos da chamada "territorialização de políticas".

3 Neste trabalho, com base nos resultados de pesquisa sobre programas sociais vinculados à escolarização no Brasil, nos anos 1990 e 2000, busca-se apresentar referências conceituais e analíticas que contribuam para a compreensão da reconfiguração da ação estatal em curso e de suas implicações para a realização de políticas referidas a direitos sociais.

Para tanto, discutimos a emergência, em escala mundial, dos chamados "programas de nova geração", bem como o novo padrão de referenciamento territorial da atuação social do Estado que eles instauram e, em seguida, discutimos as formas de uso e significação dos termos "territorialização de políticas" e "política territorializada", tendo por base a literatura relacionada à análise dos modelos de políticas que embasam, atualmente, a realização de programas sociais. Na sequência do texto, apresentamos e analisamos formas de referenciamento territorial de políticas e programas sociais em curso no Brasil. Por fim, discutimos os prováveis significados das formas contemporâneas de referenciamento territorial das políticas sociais na reconfiguração da ação estatal e na alteração dos padrões de definição e acesso a direitos sociais, com ênfase no campo ampliado da política educacional.

5 Considerando-se que a composição de parâmetros universalistas e focais marca significativamente a reconfiguração atual da atuação social do Estado, são discutidos os modelos de referenciamento territorial que fundamentam essas duas perspectivas e problematizados os significados de suas combinações, enfatizando-se o caso das mudanças no sistema educativo.

6 Metodologicamente, além de amparar-se na análise de conteúdo da literatura recente sobre os novos desenhos de políticas sociais, o trabalho tem por base uma extensa pesquisa documental referente aos programas sociais vinculados à escolarização em curso Brasil, cujos resultados foram parcialmente discutidos em trabalhos anteriores ${ }^{2}$, evidenciam alterações importantes nas referências territoriais das políticas sociais e um crescente destaque dado ao tema "territorialização de políticas".

\section{0 referenciamento territorial da atuação estatal nos "programas sociais de nova geração"}

7 A composição de parâmetros universalistas e focais marca significativamente a reconfiguração da atuação social do Estado a partir da década de 1970, quando surgem tipos de programas sociais que viriam a ser chamados de "programas de nova geração", assim definidos em função de suas significativas distinções em relação ao padrão de realização de políticas sociais anteriormente consolidado nos países capitalistas centrais, e em desenvolvimento irregular nos países capitalistas dependentes.

Como mostra Castel (1998 e 2008), nos países capitalistas centrais, as políticas sociais estruturadas nos anos de consolidação e expansão do chamado Estado de Bem Estar Social definiam-se, especialmente, por uma orientação universalista, que implicava abrangente cobertura populacional e uma organização territorial capaz de garantir o acesso regular aos bens, equipamentos e serviços.

9 Nesses países, a organização de cada política no território, na perspectiva universalista, implicou o desenvolvimento e a expansão de técnicas de delimitação e ordenamento da 
ação do Estado em todo o território nacional. Estudos como os de Henry Lefebvre (1978), sobre a organização do Estado moderno, e David Harvey (2005), sobre os diferentes modelos de planejamento e organização do espaço urbano em distintos contextos econômicos, evidenciam faces históricas relevantes das orientações e práticas de planejamento que acabaram por resultar numa extensão da divisão do território em distritos administrativos para o conjunto dessas políticas.

10 A distribuição territorial de bens, equipamentos, serviços e sua administração, regida por matriz distrital, nesse quadro, mostra-se fortemente implicada com a realização de serviços referidos a direitos segundo um mesmo padrão. Esses eram os componentes que balizavam as políticas de perfil universalista: plena cobertura populacional, segundo critérios de distribuição e administração distrital e segundo a generalização de um mesmo padrão.

11 As políticas focalizadas que emergem a partir da década de 1970 podem ser parcialmente definidas por contraste em relação a cada um desses elementos: dirigemse a públicos delimitados, administrativamente definidos segundo critérios discricionários; suas ações são diversificadas, correlativamente às especificidades dos públicos-alvo; implicam alocação seletiva de recursos; no que diz respeito ao seu escopo, mostram-se frequentemente vinculados a compensações financeiras, materiais ou formativas que em tese reduzam as desigualdades sociais; em termos territoriais, ancoram-se nas malhas distritais já constituídas, mas efetivam-se segundo critérios focalizados de localização e distribuição.

12 A demarcação de "zonas de atuação prioritária", como no caso das Zonas de Educação Prioritárias (ZEP), implantadas desde os anos inicias da década de 1980, na França (CHAUVEAU, 1982), é um caso exemplar, seja pela impressionante disseminação do modelo definido por essa política, seja pelos seus desdobramentos ${ }^{3}$ implicados com a criação de outras medidas focais mais ou menos ramificadas entre si (ROCHEX, 2011), que passam a constituir uma nova malha de atuação do Estado, de difícil mapeamento e acompanhamento.

13 As experiências relacionadas à implantação dessa lógica de zoneamento prioritário na organização de programas sociais no contexto americano (WACQUANT, 2006) e francês (CASTEL, 2008), e mesmo no contexto brasileiro (ARRETCHE, 2004 e 2010, e FLEURY, 1993, 2011 e 2013), evidenciam problemas relevantes que se desdobram dessas políticas, em termos de sua baixa ou inócua efetividade, do estabelecimento de padrões diferenciados de acesso e exercício de direitos, bem como em termos de novas dificuldades de pactuação e definição de parâmetros de autonomia e responsabilidade entre os entes constitutivos dos Estados nacionais.

$14 \mathrm{Na}$ esteira dessas mudanças, inúmeras questões de ordem conceitual, normativa e prática foram sendo colocadas em face da necessidade de progressivo discernimento sobre os critérios e os motivos que presidiriam a definição do referenciamento territorial dos novos programas. 0 exame da literatura sobre o tema evidencia relevantes questões a esse respeito. 


\section{A discussão das políticas territorializadas na literatura sobre os "programas sociais de nova geração"}

15 A análise da literatura sobre o tema, como demonstrado em trabalhos como os de Torres e Marques (2004) e Alves e Koga (2010), permite observar que a questão das estratégias territoriais como elemento estruturante de políticas sociais aparece, pelo menos, em dois tipos de discussão.

Um primeiro tipo diz respeito à incorporação de lógicas territoriais de intervenção às políticas setoriais sociais clássicas, como as de educação e de saúde, que, em decorrência dessa incorporação, passam a apresentar diferenciações locais, especialmente em áreas de concentração de pobreza.

O segundo tipo de discussão diz respeito mais especificamente às políticas focais, com ênfase na integração de ações de diferentes órgãos e secretarias de modo a ampliar as possibilidades de repercussão da ação pública nas condições de vida em cada localidade.

Observa-se, ainda, que trabalhos de diferentes perspectivas e áreas parecem partir de um consenso sobre a necessidade de que "o desenho e as estratégias de implementação das políticas sociais [levem] em conta os territórios concretos onde residem as populações a que estas políticas se destinam" (TORRES E MARQUES, 2004, p.28). As justificativas, porém, são variadas, destacando-se as expectativas: de maior proximidade entre o desenho das políticas e os problemas para os quais se dirigem; de maior efetividade na redução de desigualdades sócio-territoriais; de que a maior articulação entre os diversos programas e ações realizados em cada localidade promova uma melhor correlação entre seus custos e resultados concretos; de um melhor controle administrativo da realização de programas sociais.

Termos como "territorialização de políticas" ou "dimensões territoriais de políticas" são usados, em geral, para destacar a necessidade de recortes territoriais intra-urbanos, expressando uma lógica de focalização.

20 A análise do referenciamento territorial de programas sociais e de argumentos favoráveis à delimitação territorial da ação estatal mostra que, frequentemente, a demarcação de áreas prioritárias configura-se como estratégia principal de focalização da ação do Estado em relação à pobreza, genericamente definida. O termo “territorialização de políticas", nesse caso, apesar de frequentemente enfatizar o objetivo proclamado de consideração das especificidades de cada território no desenho das políticas, mostra-se, na prática, mais diretamente relacionado à demarcação de "zonas de atuação prioritárias" que em tese buscam compensar a produção desigual das condições de vida no território.

\section{Formas de referenciamento territorial de políticas e programas sociais em curso no Brasil.}

As pesquisas que realizamos sobre os programas sociais vinculados à escolarização ${ }^{4}$ vêm revelando uma multiplicidade e variedade de programas focais cujas delimitações de escopo e de alcance populacional e territorial mostram-se claramente vinculadas a um padrão de referenciamento territorial que conjuga: 
22 a) a malha distrital - no caso brasileiro, irregular e parcialmente descontínua constituída em correlação com as políticas orientadas para a universalização, como educação e saúde;

b) uma malha distrital de novo tipo, em constituição no campo da assistência social, configurada pelos Centros de Referência da Assistência Social (CRAS), definidos pela Política Nacional de Assistência Social (PNAS) ${ }^{5}$, instituída em 2004;

c) uma miríade de programas de formatos, alcances e propósitos variados, realizados por diferentes níveis governamentais, de forma integrada ou autônoma, que não constituem propriamente uma malha, a não ser parcialmente, e cujas diferenciações implicam formas distintas de referenciamento territorial.

Deve-se observar, neste caso, que um mesmo programa pode apresentar impressionantes oscilações internas a esse respeito, como se pode depreender do trecho abaixo transcrito de um documento relacionado à implantação de um desses programas, o Programa Projovem Adolescente:

"O referenciamento do serviço socioeducativo do Projovem Adolescente ao CRAS significa, na prática, que os coletivos de jovens serão implantados nos próprios CRAS, desde que observados alguns pré-requisitos, ou acontecerão no território de abrangência do CRAS, em outra unidade pública ou, por meio de execução indireta, em entidades de assistência social presentes neste território. De qualquer forma, garante-se, por meio do referenciamento ao CRAS, a territorialização da oferta do Projovem Adolescente ou, dito de outra forma, que o serviço seja ofertado nos territórios que, no município ou Distrito Federal, concentram as famílias (e jovens) em situação de maior vulnerabilidade social" ${ }^{6}$.

Há um grande número de programas cuja realização depende da organização distrital das políticas de largo espectro, como as de educação pública, saúde pública e assistência social, sem que isto signifique a incorporação do princípio de distribuição e alcance que rege originalmente a distritalização. Observa-se, neste caso, que novas utilidades vêm sendo atribuídas às bases administrativas e institucionais distritais. Tais bases mostram-se necessárias para a implantação de programas e ações com demarcações de alcance e distribuição territorial distintos, mas que têm como ponto comum, por vezes, o fato de serem criados, por exemplo, sem espaços e equipes próprios.

A demarcação distrital, as redes de estabelecimentos destinados à realização de serviços que as constituem, assim como as redes de instituições de pesquisa e assessoramento e, ainda, os órgãos administrativos que as vertebram, incluindo-se, neste caso, inúmeros conselhos de gestão, participação e acompanhamento de políticas, conferem uma base material (em sentido estrito) e institucional (em sentido ampliado, ou seja, englobando o conjunto de recursos de ação que permitem ao campo educativo escolar funcionar como campo especializado) sem a qual a realização do novo eixo de ações focais seria ao menos parcialmente impossibilitada.

No campo educativo escolar, essas ações focais, definidas por uma lógica fracionada de referenciamento territorial, vêm se tornando um importante recurso de expansão da oferta de escolarização, com implicações problemáticas em termos da reconfiguração do "sistema educacional". 


\section{Programas sociais focais e reconfiguração do sistema educacional brasileiro}

Uma dos principais resultados da adoção de programas sociais focais vinculados à escolarização, no Brasil, tem sido a crescente diversificação da oferta escolar. A diversificação das vias formativas em um sistema educacional não é um dado novo. É, na verdade, um elemento estruturante da constituição e organização da oferta escolar e, por conseguinte, das formas possíveis de escolarização.

1 No Brasil, porém, tal diversificação assumiu, ao longo da história, um peso significativo no delineamento de um tipo de escola centralmente definido pela desigualdade de acesso à formação escolar. Feita sob o argumento clássico de que a maior incorporação dos diferentes segmentos educacionais à escola requer a adequação da oferta a necessidades e possibilidades de escolarização distintas, a diversificação dessa oferta parece ter se constituído no Brasil menos como um mecanismo de ampliação efetiva do acesso a um tipo geral de escola, e mais como um dispositivo de diferenciação das instituições e vias de escolarização para os diferentes segmentos populacionais.

A multiplicação de programas que instituem vias diferenciadas de formação escolar, a partir da década de 1990, constituídas nos interstícios entre escolarização regular, escolarização supletiva e formação profissional, projeta-se, portanto, sobre um sistema educacional definido historicamente por uma intensa disparidade de oportunidades e experiências educacionais. Essa multiplicação é especialmente relevante para a discussão aqui pretendida, por seus potenciais efeitos objetivos e subjetivos. Afinal, enquanto as novas vias formativas vão alocando diferenciadamente os diversos segmentos populacionais na educação escolar, as variações que as distinguem qualitativamente são frequentemente postas em segundo plano por discursos que enfatizam e festejam a ampliação da oferta, das taxas de escolarização e dos anos de escolaridade da população.

3 O levantamento e análise das medidas, programas e ações instituídos pelo nível central de governo, no Brasil, a partir de meados da década de 1990, fornece um panorama impressionante da multiplicidade de vias que constituem, hoje, o quadro geral das oportunidades de escolarização. No período em questão, é possível identificar mais de 30 (trinta) programas cuja incidência sobre a escolarização se dá, inegavelmente, na forma de instituição de uma diferenciação de vias formativas que, em grande parte das vezes, longe de representarem univocamente uma expansão da escolarização, reiteram a conjugação de ampliações compensatórias e reduções que caracteriza todo o processo de expansão escolar como expansão desigual no país.

Dentre os programas criados e modificados por diferentes medidas normativas, alguns incidem sobre a escolarização regular, especialmente no caso do ensino fundamental, concorrendo para a ampliação no número de crianças e jovens escolarizados, mas segundo percursos diferenciados de formação por dentro da própria educação regular. Destacam-se, neste caso, os programas de Aceleração de Aprendizagem, o Programa de Erradicação do Trabalho Infantil (PETI), o Programa Bolsa Escola e seu substituto, Bolsa Família, o Programa Segundo Tempo e o Programa Mais Educação.

Outros programas criam diferenciações internas na escolarização de jovens e adultos, estabelecendo vias distintas com caráter e qualidade formativa igualmente distintos. Os exemplos, neste caso, são muitos, envolvendo uma multiplicidade de sucessões, fusões e 
modificações, cujo detalhamento não é possível nos limites deste artigo. Podem ser listados, neste caso, os seguintes programas: Programa Alfabetização Solidária, Brasil Alfabetizado, Programa Agente Jovem de Desenvolvimento Social e Humano, Programa Nacional de Inclusão de Jovens - Projovem (incorporando não só ao Agente Jovem, mas outros programas de linhagem próxima, como Escola de Fábrica e Saberes da Terra), Programa Nacional de Integração da Educação Profissional com a Educação Básica na Modalidade de Educação de Jovens e Adultos (Proeja) e sua mutação rumo ao Proeja FIC, Projeto de Profissionalização dos Trabalhadores da Área de Enfermagem (Profae), Programa Nacional de Educação na Reforma Agrária (Pronera), Exame Nacional de Certificação de Competências de Jovens e Adultos (Encceja), Rede Nacional de Certificação Profissional e Formação Inicial e Continuada (Rede Certific), e programas e cursos que passam a compor o Plano Nacional de Qualificação - PNQ (2003).

Há também programas que integram o campo da educação de jovens e adultos, sem, contudo, vincular-se de forma central à elevação da escolaridade. Podem ser lembrados, neste caso, os programas e cursos que passam a compor o Plano Nacional de Educação Profissional - Planfor (1995-2003), e programas variados como Juventude Cidadã, Soldado Cidadão, Pintando a Liberdade - Inserção Social por Meio da Produção de Material Esportivo, Reservista Cidadão, Mães da Paz, Projeto de Proteção dos Jovens em Território Vulnerável (Protejo) e Mulheres Mil.

Com esses programas e com as novas medidas de expansão da oferta de educação básica nas suas diferentes etapas, é possível afirmar que o maior alcance social e territorial da escola, bem como a (por vezes) maior duração da escolarização, dão-se em um contexto de uma crescente incorporação de segmentos sociais à formação escolar.

Essa maior incorporação, no entanto, vem sendo acompanhada de uma reiterada e crescente diversificação formativa que não supera (e, em diversos casos, até torna mais aguda) a tendência histórica ao descompasso entre a produção de novos e avançados requisitos e formatos de escolarização e a consolidação do acesso de grande parte da população aos requisitos mínimos de formação escolar.

Outro aspecto a destacar, portanto, é que essa diversificação formativa se dá frequentemente na forma de multiplicação de vias formativas que não têm significativa equivalência entre si, a não ser equivalência formal, observando-se, dentre outros aspectos: a intensificação de diferenças de duração e do conteúdo formativo da escolarização; a diferenciação das bases institucionais que referenciam a realização e o exercício do processo formativo; a diversificação das equipes profissionais, no que diz respeito ao seu caráter permanente ou temporário, às suas formas e requisitos de formação e treinamento, à sua remuneração e à sua estabilidade ou instabilidade.

40 A análise das características organizacionais e de aspectos das formas concretas de implementação de parte desses programas permite ainda indicar suas implicações com:

41 a) Uma complexa diferenciação institucional, que não ocorre só devido à existência de instituições educacionais distintas funcionando em estabelecimentos distintos, mas também devido à tendência, cada vez mais disseminada, de coexistência de diferentes instituições ou programas em uma mesma instalação. Observa-se, neste caso, especialmente, a reiteração de antigas práticas de utilização sistemática da infraestrutura escolar para a realização de ações muito propagandeadas, mas pouco conhecidas. Essa sobreutilização das bases institucionais para a realização de ações variadas nos seus conteúdos, formatos organizacionais e formas de gestão pode implicar, também, a necessidade de convívio cotidiano entre equipes profissionais 
constituídas a partir de critérios diferenciados e organizadas segundo regimes e condições de trabalho desiguais, incitando relações concorrenciais e tendencialmente tensas e desagregadoras;

b) Significativas alterações das condições de transparência, visibilidade, percepção e reconhecimento social da educação como serviço e como direito. Há uma nítida perda da capacidade de acompanhamento e controle social das ações e do financiamento, já que as durações variadas de cada programa, suas diferenças curriculares, sua realização por meio de parcerias entre diferentes setores governamentais (intersetorialidade), entre diferentes níveis de governo e entre instituições públicas e organizações privadas, e as frequentes mudanças nos próprios formatos de cada programa, dentre outros aspectos, dificultam o acompanhamento dos seus dados de realização e impõem limites e fragilidades às informações vinculadas aos indicadores de gestão educacional, de escolarização e de escolaridade. A própria publicização dos dados concernentes a cada programa é irregular e não raramente pouco clara, apresentando, inúmeras vezes, um caráter meramente publicitário que, longe de dar sólida visibilidade sobre o efetivo acesso à formação escolar, segundo as concretas formas e condições de escolarização, concorre mais para difundir impressões gerais de impactos não comprovados e para "borrar" o próprio significado dos dados regularmente difundidos sobre a educação básica. Essa profusão de programas e o uso reiterado de publicidade impõem uma percepção social de ampliação da ação do Estado que, no entanto, torna-se cada vez mais difícil de mensurar no que diz respeito ao alcance populacional, à duração, etc.

c) A consequente complexificação das possibilidades de agregação de usuários e de profissionais e entre usuários e profissionais, em decorrência dos baixos vínculos institucionais de ambos os segmentos e da inevitável diversificação da experiência de escolarização como experiência coletiva, compartilhada, com evidentes danos à constituição das movimentações sociais que seriam fundamentais para tensionar os governos e disputar efetivamente o conteúdo, a forma e os objetivos da política educacional e das ações que a constituem.

d) A intensificação ou reiteração, em muitos casos, do fracionamento e diversificação da formação escolar no território nacional, reeditando-se antigas assimetrias entre regiões, entre capital e interior, área urbana e área rural, áreas urbanas abastadas e subúrbios, áreas centrais e periferias, bairros e comunidades, dentre outras distinções.

\section{Considerações finais}

Apesar da ênfase no suposto caráter inovador do modelo de referenciamento territorial correlato às políticas focais, muitas proposições reiteram lógicas e termos presentes em contextos anteriores, sendo também relevante observar o uso frequente de termos que revelam propósitos pragmáticos de curto alcance, como os circunscritos à provisão de mínimos sociais, só parcialmente ocultados por discursos de proteção e direitos.

46 A difusão do tema na literatura sobre políticas sociais, especialmente as vinculadas à escolarização, indica a instauração de um padrão de organização territorial de políticas efetivamente distinto do padrão distrital, difundido e consolidado com a expansão das políticas de caráter universalista. Tal padrão é especialmente visível no modo de correlação entre forma e funções no qual se funda atualmente o sistema educativo no Brasil, marcado pela crescente conjugação entre expansão e diferenciação da escola. 
vo padrão não prescinde da organização distrital das políticas de largo espectro educação pública, saúde pública, assistência social. Parece, na verdade, constituir-se a partir de novas utilidades atribuídas às bases administrativas e institucionais distritais, necessárias para a implantação de programas e ações cuja realização se dá segundo distintas demarcações de alcance e distribuição territorial. A demarcação distrital e as redes de estabelecimentos, instituições e órgãos administrativos, organizadas em conformidade com a lógica distrital, conferem uma base material e institucional necessária à realização do novo eixo de ações que passa a constituir - até certo ponto, formal e oficialmente, mas, a partir de certo ponto, apenas como fato - o "sistema educacional brasileiro".

\section{BIBLIOGRAFIA}

ALVES, Vanice Aparecida; KOGA, Dirce. A interlocução do território na agenda das políticas sociais. Serviço Social \& Saúde (UNICAMP), 2010, vol. IX, p. 69-82.

ALGEBAILE, Eveline. Restruturação setorial da política social e composição contemporânea do campo da gestão territorial. Diez años de cambios en el Mundo, en la Geografía y en las Ciencias Sociales, 1999-2008. Actas del X Coloquio Internacional de Geocrítica, Universidad de Barcelona, 26-30 de mayo de 2008. <http://www.ub.es/geocrit/-xcol/253.htm>

ALGEBAILE, Eveline. Escola pública e pobreza no Brasil: a ampliação para menos. Rio de Janeiro: Lamparina/Faperj, 2009.

ARRETCHE, Marta. Federalismo e igualdade territorial: uma contradição em termos? Dados (Rio de Janeiro. Impresso), v. 53, p. 587-620, 2010.

ARRETCHE, Marta. Federalismo e políticas sociais no Brasil: problemas de coordenação e autonomia. São Paulo em Perspectiva (Impresso), 2004, vol. 18, n.2, p. 17-26.

CASTEL, Robert. As metamorfoses da questão social: uma crônica do salário. Petrópolis: Vozes, 1998.

CASTEL, Robert. A discriminação negativa - Cidadãos ou autóctones? Petrópolis: Vozes, 2008.

FLEURY, Sonia. Do welfare ao warfare state. Le Monde Diplomatique Brasil, 2013, vol. 67, $01 \mathrm{fev.}$

FLEURY, Sonia. Direitos sociais e restrições financeiras: escolhas trágicas sobre universalização. Ciência e Saúde Coletiva (Impresso), 2011, vol. 16, p. 2686-2688.

FLEURY, Sonia. Estado latino-americano e políticas: limitações e tendências na conformação da cidadania e do Estado. Planejamento e Políticas Públicas (IPEA), dezembro 1992, no 8, p. 177-194.

HARVEY, David. A Produção Capitalista do Espaço. São Paulo: Anna Blume, 2005.

LEFEBVRE, Henry. De l'État 4. Les contradictions de l'Etat moderne. Paris: Union Générale d 'Éditions, 1978.

ROCHEX, Jean-Yves. As três idades das políticas de educação prioritária: uma convergência europeia? Educação e Pesquisa. Dez. 2011, vol.37, noํ, p. 871-882. 
RUMMERT, Sonia Maria; ALGEBAILE, Eveline; VENTURA, Jaqueline. Educação e formação humana no cenário de integração subalterna. Revista Brasileira de Educação (Impresso), 2013, vol. 18, p.

717-738.

\section{NOTAS}

1. Primariamente, o termo "referenciamento" indica o conjunto de coordenadas que balizam ou permitem identificar a localização de algo no espaço. Partimos desse significado geral do termo, mas também de sua utilização nos documentos normativos e instrucionais de programas sociais, para nos referirmos, em geral, a uma significativa variedade de referências territoriais (de localização, de padrões de distribuição, mas também relativas às especificidades de determinadas áreas) que incidem nas definições do alcance, da cobertura e do escopo dos programas estudados. 2. Particularmente em Algebaile, 2008 e 2009, e em Rummert, Algebaile e Ventura, 2013.

3. Aspectos relevantes do desdobramento das medidas relacionadas à criação das zonas prioritárias podem ser encontrados no documento do Tribunal de Contas da França (Cour des Comptes), intitulado: A articulação entre os dispositivos da política da cidade e a educação nacional nos quarteirões sensíveis. Comunicação dirigida à comissão de finanças do Senado. Paris, 2009. (L'articulation entre les dispositifs de la politique de la ville et de l'éducation nationale dans les quartiers sensibles. Communication adressée à la commission des finances du Sénat).

4. Em um primeiro momento, a pesquisa dessas medidas, programas e ações foi realizada por meio de projeto vinculado ao Programa de Prociência (2009-2012) e a estágio pós-doutoral realizado de 2009 a 2010, e aprofundada em trabalho associado coordenado pela Prof ${ }^{\mathrm{a}}$ Sonia Rummert, com a participação da Prof ${ }^{\mathfrak{a}}$ Jaqueline Ventura, ambas da Universidade Federal Fluminense, com vistas à consecução de trabalho encomendado pelo GT Trabalho e Educação da Associação Nacional de Pesquisa e Pós-Graduação em Educação - ANPED, em 2011. Os resultados desse trabalho, apresentados em Rummert, Algebaile e Ventura, 2012, envolvem a identificação de 36 (trinta e seis) programas sociais ou educacionais, instituídos a partir de 1994, e modificados por diferentes medidas normativas. A partir de 2012, por meio de pesquisa vinculada ao Programa de Prociência da UERJ e ao Programa Jovem Cientista do Estado, da FAPERJ, estão sendo aprofundadas as questões relativas às referências territoriais que balizam o escopo, o alcance populacional e a escala de cobertura dos programas.

5. Brasil. Ministério do Desenvolvimento Social e Combate à Fome. Conselho Nacional de Assistência Social - CNAS. Resolução no 145 , de 15 de outubro de 2004. Aprova a Política Nacional de Assistência Social - PNAS. Diário Oficial da União, 28/10/2004.

6. Brasil. Ministério do Desenvolvimento Social e Combate à Fome. Coordenação Nacional do Programa Projovem Adolescente. Informe Técnico Sobre o Referenciamento 2012 do Projovem Adolescente. <http://www.mds.gov.br/assistenciasocial/protecaobasica/servicos/projovem/ referenciamento-2012>

\section{RESUMOS}

A emergência dos chamados "programas sociais de nova geração", disseminados em escala mundial a partir dos anos 1980, tem implicado significativas mudanças nas formas de 
referenciamento territorial da atuação social do Estado. A distritalização da ação estatal, relacionada à perspectiva universalista, persiste na organização de algumas políticas, mas tem sido cada vez mais substituída ou complementada por um padrão de organização da ação definido pela delimitação de áreas de atuação prioritária. Na literatura sobre esses programas, termos como "territorialização de políticas" e "política territorializada" passam a ser frequentemente usados, apesar de apresentarem sentidos distintos. A pesquisa de formas de referenciamento territorial de programas sociais vinculados à escolarização, no Brasil, permite evidenciar relevantes aspectos da reconfiguração do sistema educacional brasileiro, indicativos de mudanças mais abrangentes na ação estatal e nos padrões de definição e acesso a direitos sociais.

The rising of so-called "new generation of social programs" spread worldwide since the 1980's have been causing significant changes in the nature of territorial referencing in the government's social actions. District apportionment of the state's action related to universalistic perspective endures in the organization of some policies, but has been increasingly replaced or supplemented by a pattern of the action's organization defined by demarcation of areas for prioritized action. Literature on these programs frequently use terms such as "policy territorialization" and "territorialized policy", despite the fact that they have different meanings. The research of territorial referencing aspects concerning social programs bound to education in Brazil, allows to highlight relevant aspects of the Brazilian educational system's reconfiguration, signs of comprehensive changes in the state's action and patterns of definition and access to social rights.

La emergencia de los llamados "programas sociales de nueva generación", diseminados en escala mundial desde los años 1980, ha implicado significativas mudanzas en las formas de referenciamento territorial de la actuación social del Estado. La organización distrital de la acción estatal, relacionada a la perspectiva universalista, persiste en la organización de algunas políticas, pero ha sido más sustituida o complementada por un padrón de organización de la acción definido por la delimitación de áreas de actuación prioritaria. En la literatura sobre eses programas, termos como "territorialización de políticas" y "política territorializada" pasan a ser frecuentemente usados, aunque presenten sentidos distintos. La investigación de formas de referenciamento territorial de programas sociales vinculados a la escolarización, en Brasil, permite demostrar relevantes aspectos de la reconfiguración del sistema educativo brasileño, indicativos de mudanzas más amplias en la acción estatal y los padrones de definición y acceso a derechos sociales.

La dissemination mondiale des «programmes sociales de nouvelle génération » à partir des années 1980 a provoqué des changements significatifs dans la territorialisation d'action sociale de l'État. Liée à une perspective universaliste, la districtalisation de cette action persiste encore. Néanmoins, elle est déplacée ou complémentée chaque fois plus par un modèle d'aménagement responsable pour la délimitation de zones d'actions prioritaires. Dans la littérature consacrée à ce sujet, des concepts comme "territorialisation de politiques» et "politique territorialisée » sont fréquents - en dépit de ces sens ne soient pas les mêmes. Au Brési, la recherche sur la territorialisation des programmes sociales attachés à l'école permet d'évidencer des traits importants concernants à la réconfiguration du système scolaire brésilien, en exprimant des changements les plus élargies de l'action étatique et des formes d'accès aux droits sociales. 
ÍNDICE

Mots-clés: politiques publiques, système scolaire, programmes sociales, politique sociale, questions sociales

Palavras-chave: políticas territorializadas, programas sociais, sistemas educativos, política social, questão social

Keywords: territorialized policy, social programs, educational systems, social policy, social issues

Palabras claves: políticas territorializadas, programas sociales, sistemas educativos, la política social, los problemas sociales

\section{AUTORES}

\section{EVELINE ALGEBAILE}

Professora Adjunta da Universidade do Estado do Rio de Janeiro (UERJ). Faculdade de Formação de Professores. PPG em Políticas Públicas e Formação Humana (PPFH). PPG em Educação Processos Formativos e Desigualdades Sociais (PPGEdu - PFDS). ealgebaile@gmail.com

\section{GUSTAVO LEITE DE ARAÚJO DA SILVA}

Licenciado em Geografia pela FFP/UERJ. Professor da Educação Básica em Magé/RJ. gustavoleite1992@gmail.com

\section{TACÍLIO FAGUNDES}

Licenciando em Geografia na FFP/UERJ. Bolsista de Iniciação Científica do CNPq. tacilio_256@hotmail.com 